\title{
Specific predictors of length and frequency effects in German beginning readers: testing component processes of sublexical and lexical reading in the DRC
}

\author{
Jana Hasenäcker ${ }^{1,2}$ (D) $\cdot$ Sascha Schroeder ${ }^{1,3}$
}

Accepted: 27 December 2021 / Published online: 3 February 2022

(c) The Author(s) 2022

\begin{abstract}
Reading a word requires several component processes. The dual route cascaded (DRC) model provides a characterization of these component processes and their involvement in different reading routes. We tested how relevant precursor skills associated with these component processes predict the use of the sublexical and lexical route in beginning readers of a transparent orthography. More than 100 German first graders performed a battery of tasks tapping into precursor skills associated with the DRC components. Using factor analysis, we first verified that the tasks can be attributed to three sets of skills, capturing visual, sublexical, and lexico-semantic components, as the DRC suggests. We then used these sets of skills to predict differences in the reliance on sublexical and lexical reading in second grade as indicated by length and frequency effects. Results show that the set of sublexical skills in first grade especially predicts differences in the recognition of long frequent words at the end of second grade, whereas the set of lexico-semantic skills predicts differences in the reading of long infrequent words. The findings corroborate the attribution of specific precursor skills to the sublexical and lexical route and reveal their distinct impact on sublexical and lexical reading in beginning readers. The work thus empirically informs the developmental version of the DRC, especially regarding variability in trajectories of reading acquisition.
\end{abstract}

Keywords Lexical processing $\cdot$ Precursor skills $\cdot$ Reading acquisition $\cdot$ Sublexical processing $\cdot$ Word recognition

Jana Hasenäcker

janahasenaecker@gmail.com

1 MPRG Reading Education and Development, Max Planck Institute for Human Development, Berlin, Germany

2 Present Address: Linguistics Departement, University of Erfurt, Erfurt, Germany

3 Educational Psychology Departement, Georg August University of Göttingen, Göttingen, Germany 


\section{Introduction}

Reading a word requires processing of visual, orthographic, phonological, and semantic information. These component processes can be involved in word reading to different degrees, depending on reading experience and language. In this study, we aimed to understand how precursor skills associated with different component processes of reading in the (developmental) DRC (Coltheart et al., 2001; Pritchard et al., 2018) distinctly predict the relative use of the sublexical versus lexical route in beginning readers of German. We use an approach that is novel in two ways: first, because it combines the assessment of precursor skills with experimental lexical decision data in a longitudinal fashion, and secondly, because it integrates a theorydriven selection of tasks with a data-driven analysis procedure.

\section{Reading development in the dual route cascaded model}

In the last decades, several models about the word recognition process have evolved (cf. Castles et al., 2018), the three most prominent ones being the dual route cascaded (DRC) model (Coltheart et al., 2001; for a German version: Ziegler et al., 2000), the connectionist dual process model (CDP+, Perry et al., 2019), and the connectionist triangle model (Harm \& Seidenberg, 2004). Importantly, they all encompass a phonological, an orthographic, and a semantic module and some kind of "division of labor" between these, depending on the lexical status (word vs. nonword) or reader's familiarity with the word (known vs. novel), as well the reading expertise (beginning vs. skilled reader).

All these models were originally designed for skilled reading, not with a focus on development. The DRC, for example, can be understood as a static model of an archetypical skilled reader. It distinguishes between two reading routes: a sublexical and a lexical one. The sublexical route uses grapheme-phoneme conversion (GPC) rules to decode nonwords letter by letter. The lexical route is used for recognizing words that have a representation in the orthographic lexicon. It can be assumed that the sublexical route is dominantly used by children in the very beginning of reading acquisition and the lexical route comes into play with experience (cf. Jackson \& Coltheart, 2001). However, the original DRC lacks a mechanism to model this change over time. To address this, recent attempts have been made to explicitly implement developmental extensions of the DRC that include a developmentally plausible learning mechanism. The ST-DRC by Pritchard et al. (2018) considers that novice readers start without an orthographic lexicon and first learn GPC rules, usually through explicit instruction. They assume a "self-teaching" mechanism (Share, 1995, 1999) for the slow building of the orthographic lexicon: successful decoding through the sublexical route via GPC rules allows the set-up of representations in the orthographic lexicon. When the orthographic lexicon grows over time, children increasingly recognize words through the lexical route. Similar developmental implementations exist for the CDP + (Perry et al., 2019; Ziegler et al., 2014) and the triangle model (Chang \& Monaghan, 2018; Chang et al., 2019). Although the exact 
implementation is different, the underlying principle is similar in all three models, i.e., that developing readers successively build up orthographic representations by using basic decoding rules and some self-teaching mechanism.

Visual, phonological, orthographic, and semantic component skills may be required to different extents in the sublexical and lexical route. For example, visual processing should be equally critical in reading along the sublexical and the lexical route to identify letters. Phonological processing should be of main importance in the sublexical route, where GPC rules need to be used to translate letters into phonemes and then assemble phonemes to words. Orthographic processing should be involved mostly in the lexical route to recognize known whole-words. Thus, certain sets of skills might be subsumed as specific predictors for the sublexical or lexical route, respectively.

\section{Precursors of reading development}

A fundamental stream of reading research has been dedicated to the investigation of cognitive and language-related abilities at the onset of schooling that predict reading ability later in development. Among the most prominent and widely studied precursor skills are phonological awareness and rapid automatized naming (Caravolas et al., 2012; de Jong \& van der Leji, 1999; Ennemoser et al., 2012; Moll et al., 2014; Torgesen et al., 1997; Wagner \& Torgesen, 1987; for a review see Melby-Lervåg et al., 2012; Araújo et al., 2015). Phonological awareness refers to the ability to recognize and manipulate the sound structure of words and is thought to enable the child to understand and systematically exploit mappings between graphemes and phonemes (De Jong \& van der Leij, 2003). Rapid automatized naming refers to the ability to produce the names of a limited set of sequentially presented stimuli and is thus thought to reflect efficiency of serial processing and phonological assembly (Landerl \& Wimmer, 2008).

While both phonological awareness and rapid automatized naming are of great general importance across all alphabetic languages, their precise weight may vary as a function of orthographic transparency. Orthographic transparency refers to how consistent the mappings between phonemes and graphemes are: German has a more transparent orthography than English due to its mostly consistent graphemephoneme correspondence (e.g., Rau et al., 2016; Schmalz et al., 2015). While some studies show a similar contribution of phonological awareness across languages (e.g., Caravolas et al., 2012), many studies suggest that its impact might be stronger and longer in opaque orthographies like English as compared to more transparent orthographies like German (e.g., Landerl \& Wimmer, 2008; Landerl et al., 2018; Moll et al., 2014; Ziegler et al., 2010). Rapid automatized naming, by contrast, has been suggested to be a relatively better predictor in reading of transparent than opaque orthographies (Araújo et al., 2015; Landerl \& Wimmer, 2008; Landerl et al., 2018; Moll et al., 2009, 2014). This might also resemble the relative reliance on the phonological (sublexical) versus lexical route that differs as a function of orthographic transparency (Schmalz et al., 2015). 


\section{Length and frequency effects in beginning readers}

The use of the sublexical and lexical route in reading is often investigated by comparing word- and nonword-reading. In languages with a transparent orthography, like German, this comparison is less conclusive because reading of both words and nonwords can be read correctly via the sublexical route and their reading becomes highly accurate early in development (e.g., Landerl et al., 1997). Consequently, other measures are needed to tap the underlying processes (Ziegler et al., 2003). Theoretically important marker effects of the involvement of sublexical versus lexical processing are length and frequency effects. Because the time needed for sublexical decoding increases with number of letters, this route is typically associated with a pronounced length effect (Coltheart et al., 2001). Repeated successful sublexical decoding of a word allows children to form a corresponding orthographic representation (self-teaching; Share, 1995). Because the lexical route is based on the direct recognition of such orthographic representations, words that are encountered very often are activated faster within the lexical route, leading to a frequency effect (Coltheart et al., 2001). The relative involvement of the sublexical and lexical route is therefore characterized by the strength of those marker effects (Hasenäcker et al., 2019).

Length effects in beginning readers have gotten a fair amount of attention. They have found to be especially strong in beginning readers and decrease with reading experience in both transparent and opaque orthographies and in both naming (i.e., reading a word aloud) and lexical decision (i.e., deciding whether a letter string refers to an existing word) (e.g., Burani et al., 2002; Martens \& de Jong, 2006; Spinelli et al., 2005; van den Boer et al., 2012; 2013; Zoccolotti et al., 2005). Van den Boer et al. (2013) examined the relationship between the length effect as a marker for sublexical reading and phonological skills in Dutch second-graders. They found that phonological awareness and visual attention span modulated the length effect, while rapid naming influenced overall reading speed.

The frequency effect as a marker for the lexical reading route, albeit being extensively studied for adults, is less well studied in children, and is often poorly differentiated from the lexicality effect. This might partly be because age-appropriate frequency measures are rarely available, complicating the creation of appropriate stimulus materials. Burani et al. (2002) are one of the few who investigated frequency effects in both naming and lexical decision. They found that frequency effects were present in both tasks in all children in their study (third to fifth grade) but were more pronounced in lexical decision than naming. This shows that lexical decision might draw on lexical processing to a larger degree and is thus of special importance for the study of sublexical versus lexical processing (cf. van den Boer \& de Jong, 2015). It also shows that frequency effects occur relatively early in reading development.

Studying length and frequency effects in combination is important because they might interact. For high frequency words, which are read often, children might form an orthographic representation early in reading development. Hence, they can recognize these words via the lexical route, for which length plays a subordinate role. For low frequency words, which are not encountered often, children might not have 
formed an orthographic representation yet. Hence, they need to decode those via the sublexical route, where length has a stronger impact on word reading. Consequently, when investigating the reliance on sublexical and lexical reading in development, effects of length and frequency need to be jointly considered. However, this is rarely done and the available evidence is mixed with some studies not finding an interaction between length and frequency in developing readers (e.g., Burani et al., 2002; Hasenäcker et al., 2019; Huestegge et al., 2009; Rau et al., 2014) while other studies report stronger length effects for low-frequency words (e.g., Hyönä \& Olson, 1995; Tiffin-Richards \& Schroeder, 2015). It seems that the size of the interaction effect is moderated by various factors, including orthographic transparency (with stronger length $\mathrm{x}$ frequency interactions in more transparent languages), task (with tasks emphasizing sublexical processing leading to weaker interaction effects), and reading skill (with more skilled readers showing stronger interaction effects).

\section{Bridging precursor skills and reading in the DRC}

So far, the predictive relationship between different precursor skills and marker effects of length and frequency has not been examined systematically. In a related approach focusing on dyslexic readers only, Ziegler et al. (2008) and Perry et al. (2019) illustrate how each of the component processes of the DRC can be matched with a single task to measure a specific component skill.

Ziegler et al. (2008) explored the impact of single skills on sublexical and lexical reading by (1) relating dyslexic children's deficits in these skills to their reading performance on regular and irregular words, and (2) simulate the effect of deficits in these skills in the computational implementation of the DRC. The results suggest that dyslexic readers often show deficits in multiple component skills, affecting reading along both the lexical and sublexical route. Nevertheless, some skills were associated more strongly with problems in one route. For example, poor phoneme awareness reflecting deficits in grapheme-phoneme mapping in the sublexical route was associated with both phonological and surface dyslexia, whereas poor picture naming associated with the phonological lexicon in the lexical route was more associated with surface dyslexia.

Building on this idea, Perry et al. (2019) used performance on three component tasks to simulate the individual reading profiles of children with dyslexia, suggesting that the interplay of deficits in multiple components affects reading outcome. Increasing efficiency in phonological processing tended to be more beneficial for nonword reading in the sublexical route whereas increasing vocabulary skills tended to be more beneficial for irregular word recognition through the lexical route.

Both studies, however, are not directly informative for interindividual differences in typical, unimpaired readers within the framework of the developmental DRC. Furthermore, while the studies establish the theoretical matching of different tasks to components of the DRC, they do not verify the structure of sets of skills and their attribution to components empirically. Lastly, they do not use longitudinal data, thus compromising the explanatory power of potential causal relations of variability in component skills and reading trajectories. 


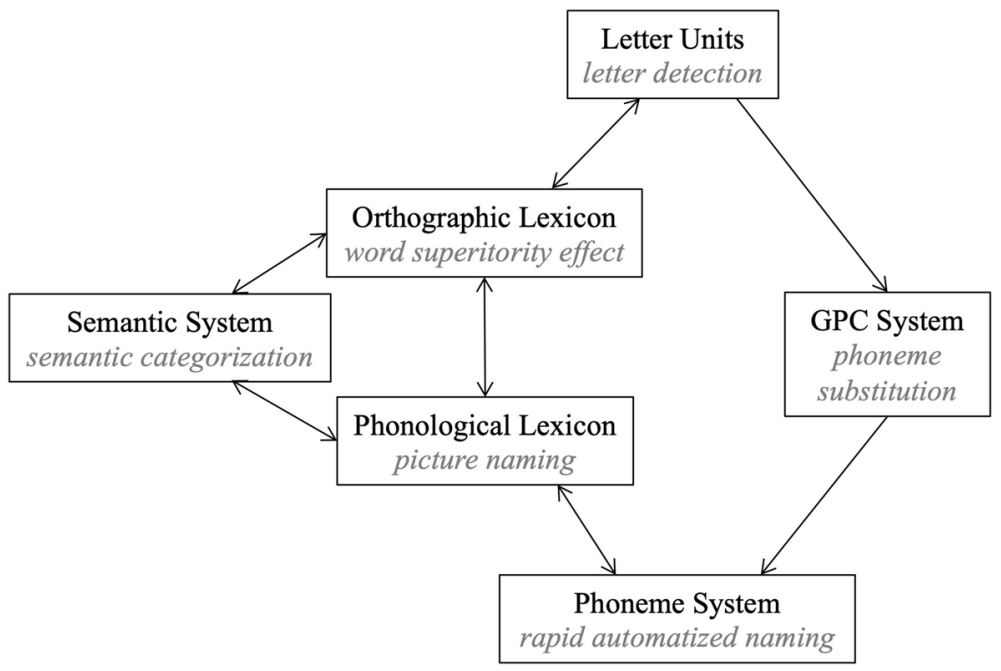

Fig. 1 Overview over components of the DRC ( adapted from Coltheart et al., 2001) and tasks associated with each of the components

\section{The present study}

As became clear, children's precursor skills have been investigated extensively and have been related to various reading tasks. Similarly, there are several studies that have investigated length and frequency effects in developing readers. Crucially, effects of precursor skills on such marker effects have rarely been investigated in a systematic way. The important and unique contribution of the present study is that it combines these two strands with the main purpose to test the relations between specific precursor skills of reading and interindividual differences in the efficiency of the sublexical and lexical route in beginning readers. To this end, we used a set of measures of children's precursor skills that have been shown to be related to length and frequency effects. The selection of tasks was based on Ziegler et al. (2008) who established that different cognitive tasks are differentially related to the strength of prelexical, sublexical, and lexical processes in the DRC (see Fig. 1). In our study, we used the same tasks in order to measures children's precursor skills at the beginning of formal reading instruction in first grade. We used factor analysis to investigate the underlying structure of the measures and verified that a solution with three factors fit the data well and was theoretically plausible, as the three factors were representing prelexicalvisual, sublexical-phonological, and lexico-semantic skills, respectively. At the end of second grade, the same group of children performed a lexical decision task in which word length and frequency were manipulated. We were particularly interested in the question whether the three precursor factors would moderate the strength of marker effects of the sublexical route (i.e., length effects) and lexical route (i.e., frequency effects). Thus, our study combines a) the validation of a theoretically-motivated assumption with a data-driven analysis strategy with b) a 
longitudinal design in which the long-term effects of different precursor skills is related to the strength of sublexical and lexical processing in the DRC.

\section{Method}

\section{Participants}

Data was acquired as part of the larger longitudinal project Orthographic Processing in Reading Acquisition (OPeRA). It started with 132 children from four schools in an urban area. All testing sessions took place in the schools during regular school hours. Children were tested individually in a separate and quiet room by the first author or a specifically trained research assistant. Written consent for participation was obtained from parents prior to the beginning of the project and oral consent was asked from children at the beginning of each testing session. At the first testing point, children were in the middle of first grade. At the end of second grade $2,1.5$ years later, data was acquired from 121 children of the initial sample. Children dropped out because they repeated the first school year, changed to a different school, or moved away. Further, 15 children were excluded from data analysis as their performance on the lexical decision task did not exceed chance level $(<50 \%$ correct) and one child had to be excluded as data from the precursor skills tasks were incomplete. Thus, analyses on data from 107 children (55 female, 50 male, $\mathrm{M}_{\mathrm{age}}=5.98, \mathrm{SD}=0.34$ at Grade 1 testing point) are presented.

The final sample was characterized by a medium to high socio-economic background, as approximated by parents' educational background and occupational situation, which were assessed in a questionnaire the parents filled out when giving consent to the study. All children had acquired German prior to school entry as their dominant language, as indicated in the parent questionnaire. Reading ability at the second grade testing point was normally distributed $(M=48.46, S D=20.34)$ and grade-appropriate (norm sample: $M=46.43, S D=17.70$ ), as indicated by a standardized one-minute word reading test (SLRT; Moll \& Landerl, 2010). There were no children with special needs in the participating classes and hence in our sample, at least as far as diagnosed by the time of the study.

\section{DRC component tasks}

The DRC component skills were tested in the middle of first grade (November/ December 2013). The tasks-letter search, picture naming, phoneme replacement, rapid automatized naming and semantic classification-were matched to the DRC components as depicted in Fig. 1. The purpose of this was to directly relate precursor skills to reading routes in the DRC and hence investigate which set of skills in grade 1 can uniquely predict length and frequency effects in second grade. The matching of tasks to DRC components followed Ziegler et al. (2008; also see Perry et al., 2019) in combination with theoretical considerations on what each task measures and how this can be associated with the components of the DRC. The measurements 
Table 1 Performance in the DRC component tasks (RTs to correct answers only)

\begin{tabular}{llllll}
\hline & M & SD & Min & Max & Reliability \\
\hline $\begin{array}{l}\text { Letter search: Strings } \\
\text { Accuracy (\%) }\end{array}$ & 87.05 & 11.58 & 40.00 & 100.00 & \\
RT (ms)* & 2307 & 549 & 818 & 4262 & $.86^{\mathrm{a}}$ \\
$\begin{array}{l}\text { Letter search: Pseudowords } \\
\text { Accuracy (\%) }\end{array}$ & 86.33 & 11.61 & 30.00 & 100.00 & \\
RT (ms) & 2324 & 547 & 764 & 3877 & $.84^{\mathrm{a}}$ \\
Letter search: Words & & & & & \\
Accuracy (\%) & 89.29 & 8.92 & 60.00 & 100.00 & \\
RT (ms) & 2197 & 503 & 922 & 3700 & $.84^{\mathrm{a}}$ \\
Letter search: Word superiority effect & & & & & \\
Accuracy benefit (\%) & 2.95 & 10.46 & -20.00 & 35.00 & \\
RT benefit (ms)* & 127 & 326 & -1130 & 594 & $.64^{\mathrm{a}}$ \\
$\begin{array}{l}\text { Picture naming } \\
\text { Accuracy (\%) }\end{array}$ & 86.61 & 7.48 & 56.00 & 98.00 & \\
RT (ms)* & 1241 & 200 & 850 & 1877 & $.87^{\mathrm{b}}$ \\
Phoneme substitution & & & & & \\
Score (number of correct items)* & 2.00 & 1.89 & 0 & 7 & $.73^{\mathrm{b}}$ \\
$\begin{array}{l}\text { Rapid automatized naming } \\
\text { RT (ms)* }\end{array}$ & 18,493 & 7242 & 10,240 & 47,490 & $.84^{\mathrm{a}}$ \\
$\begin{array}{l}\text { Semantic categorization } \\
\text { Accuracy (\%) }\end{array}$ & & & & & \\
RT (ms)* & 93.38 & 11.26 & 90.00 & 100.00 & $.90^{\mathrm{b}}$ \\
\hline
\end{tabular}

*Variable of interest used in the factor analysis

${ }^{\text {a }}$ Split-half correlation corrected for attenuation

${ }^{\mathrm{b}}$ Cronbach's $\alpha$

were inspired by other studies or standardized tests and adapted to the specific needs and constraints (in terms of time, language, difficulty, etc.) of our study. More specific justifications for our choices are given in the task descriptions below. The computerized experiments were run on a $15^{\prime \prime}$ laptop monitor with a refresh rate of $60 \mathrm{~Hz}$. The performance on the single DRC component tasks is presented in Table 1 and correlations between the component tasks are presented in Table 2.

Letter search The letter search task was used to investigate efficiency of letter unit as well as lexical processing, following Ziegler et al. (2008). In this task, children were required to search for a target letter within a stimulus, which could be a fiveletter word (e.g., KRAFT), pseudoword (e.g., PLOFT) or unpronounceable string (e.g., SNZLU). Each trial started with a black 20-point fixation cross in the center of a white computer screen for $500 \mathrm{~ms}$, which was replaced by a single target letter for $1000 \mathrm{~ms}$, followed by one of the stimuli (word, pseudoword, or unpronounceable string). This stayed on the screen until participants pressed a button to indicate whether the previously shown target letter was present in the stimulus (" $\mathrm{K}$ " on a 


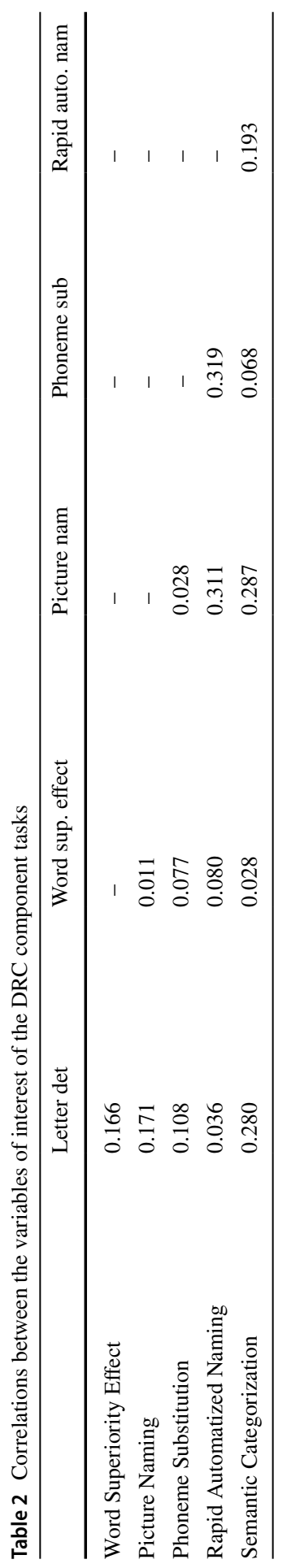


standard keyboard marked green) or not ("D" marked red). In total, there were 60 trials - 20 from each stimulus condition (word, pseudoword, string)—of which half contained the target letter and half did not. Identity and position of the target letter in the stimulus were matched across stimulus conditions. Errors and response times were recorded by the experimental program Inquisit.

There were two measures that we derived from the letter search task. First, to investigate the efficiency of letter unit processing without lexical activation, we used letter detection time. That is, the average speed with which a child can detect a target letter within an unpronounceable letter string (Ziegler et al., 2008). Secondly, to investigate efficiency of the orthographic lexicon, we used the word superiority effect. This effect refers to faster identification of a target letter when it is presented in a real word (Reicher, 1969). It is thought to arise due to efficient feedback from the orthographic lexicon and is thus a measure of its functioning (Ziegler \& Jacobs, 1995; Ziegler et al., 2008). It is measured as the average time benefit for correct responses to target letters in words as compared to pseudowords for each child $(\Delta \mathrm{RT}$ word-pseudoword).

Picture naming To test retrieval from the phonological lexicon without the need for any kind of reading, we used picture-naming speed (Glaser, 1992; Swan \& Goswami, 1997). In this task children were presented with a black-and-white drawing of an object in isolation on the computer screen and were asked to name the object as quickly and as accurately as possible. In total, 60 pictures from the International Picture-Naming Project (http://crl.ucsd.edu/ aszekely/ipnp/; Szekely et al., 2004) had to be named. The number of pictures was motivated by balancing the requirement for a reliable estimate with the attention and motivation span of the children. The responses were recorded, and naming times were measured manually from the onset of the picture presentation to the onset of speech using the Audacity software. Accuracy was also coded manually. The variable of interest was the response time in correct trials.

Phoneme substitution To investigate children's phonological awareness, we used a task that tests children's ability to manipulate phonemes. Phoneme manipulation tasks like this are widely claimed to reflect meta-linguistic phonological awareness, which helps to establish and use grapheme-phoneme mappings in reading acquisition (e.g., Wagner \& Torgesen, 1987). In the phoneme substitution task children were asked to manipulate phonemes within words and pseudowords. Seven items were taken from the vowel substitution subtest of the BAKO (Stock et al., 2003), a German standardized test battery for the assessment of phonological awareness in elementary school children. The examiner read aloud a word or pseudoword and participants were instructed to orally replace every "/a/" with "/i/" (e.g. "/sand/"- -" sind/"). The task was terminated when a participant gave three wrong answers consecutively. The number of correctly manipulated items was recorded as the variable of interest.

Rapid automatized naming To measure speed of phonological assembly and processing, we used a rapid automatized naming (RAN) task with digits (e.g., Moll et al., 2009; Torgesen et al., 1997). In our RAN task participants were required to name a series of digits as fast as possible. Precisely following the procedure of Pauly et al. (2011), Arabic digits (1, 2, 3, 4, 5, 6) were presented black on white in 
randomized order in two rows of nine items each, such that each item appeared three times in total. Participants were instructed to name the two rows as quickly as possible. The responses were recorded and naming times were measured manually from the onset of the presentation of the items until naming of the last stimulus using the Audacity software. There was no time-out or cut-off. Naming errors were also recorded but were discarded from further analysis because they were extremely rare (five children made a single error, no child made more than one error). Prior to the test trial, participants named all numbers from one to six once to assure their knowledge. We also conducted a version of the RAN, in which children had to name onesyllable objects (ice cream, ball, dog, tree, fish, house; Pauly et al., 2011). We used the object version to check the reliability of the task (cf. Table 1), but only used the number version in our analyses as it has been shown to have a stronger relationship to reading (Araújo et al., 2015).

Semantic categorization To measure semantic processing without the need for any kind of reading, we used an auditory semantic categorization task (Ben-Dror et al., 1995). In this task children were auditorily presented with a word and were asked to indicate via button press whether the word denotes an animal ("K" on a standard keyboard marked green) or not ("D" marked red). There were 32 trials in total (16 animal words and 16 distractors). Word length ranged between five and seven $(\mathrm{M}=4.45, \mathrm{SD}=1.29)$ phonemes and normalized lemma frequency between eight and $451(\mathrm{M}=93.32, \mathrm{SD}=110.47)$. Length and frequency were matched across animal and distractor words. Errors and response times were recorded by the experimental program Inquisit. The variable of interest was the response time in correct trials.

\section{Lexical decision task}

Lexical decision performance was tested in the end of Grade 2 (May/June 2015). For the lexical decision task (LDT), we used a $2 \times 2$ design, orthogonally manipulating length and frequency. 64 words were chosen from the stimulus list of the Developmental Lexicon Project (Schröter \& Schroeder, 2017). The number of words was determined by finding a compromise between power (i.e., enough items in each condition to ensure reliability of potential effects) and feasibility (i.e., making the task manageable for children) and was informed by previous comparable studies (Burani et al., 2002; van den Boer et al., 2012). Half of the words were four letters long and the other half were eight letters long. Also, half of the words were of high frequency (HF) (normalized lemma frequency: $M=78.59, S D=70.86, \min =18.27$, $\max =336.30$, Zipf scale: $M=4.90, \min =4.26, \max =5.53$; Brysbaert et al., 2018) and the other half were of low frequency (LF) $(M=7.68, S D=3.97, \min =1.12$, $\max =14.62$; Zipf scale: $M=3.89, \min =3.08, \max =4.16)$. Frequency was matched over short and long words, $t=0.79, p=0.43$. Lexical characteristics were taken from childLex (Schroeder et al., 2014), a corpus of children's books comprising ten million words. Furthermore, 64 pronounceable pseudowords were taken from the stimulus list of the Developmental Lexicon Project (Schröter \& Schroeder, 2017). They were originally created using Wuggy (Keuleers \& Brysbaert, 2010), a computer 
Table 3 Factor loadings of each component task to the three factors of the factor analysis

\begin{tabular}{llll}
\hline & $\begin{array}{l}\text { Factor 1 } \\
\text { SUB }\end{array}$ & $\begin{array}{l}\text { Factor 2 } \\
\text { LEX }\end{array}$ & $\begin{array}{l}\text { Factor 3 } \\
\text { VIS }\end{array}$ \\
\hline Phoneme substitution & .452 & & \\
Rapid automatized naming & .806 & .457 & \\
Semantic categorization & & .529 & \\
Picture naming & & .551 & \\
Letter detection & -.231 & .350 & .905 \\
Word superiority effect & .135 & & .240 \\
Variance explained & $16 \%$ & $16 \%$ & $15 \%$ \\
\hline
\end{tabular}

program that generates pseudowords obeying a language's given constraints (i.e., subsyllabic structure, transition frequencies). The pseudowords were matched to the words on relevant lexical characteristics (i.e., number of letters, number of syllables, OLD20).

The experiment was run on a 15" laptop monitor with a refresh rate of $60 \mathrm{~Hz}$. The stimuli were presented in the center of the screen in white 20-point Courier New font on black background. Each trial started with a 500-ms fixation cross, followed by the presentation of a word or pseudoword, which remained on the screen until a response was made by the participant. Participants were instructed to decide as quickly and as accurately as possible whether the presented stimulus was an existing German word or not and indicate the decision by pressing the D or the K key on a standard keyboard, marked red and green. Accuracy and response time were recorded. Four practice trials with feedback (right or wrong answer) were given prior to the experimental trials. After half of the items, participants had a break timed by the experimenter.

\section{Results}

\section{Factor analysis of the DRC component tasks}

To verify the underlying structure of the different tasks and to ascertain their relationships to the components of the DRC we performed a factor analysis in $\mathrm{R}$ ( $\mathrm{R}$ Development Core Team, 2008) with a varimax rotation on the z-transformed scores from the six measures. The optimal number of factors to be used was three, as determined with the nFactors package (Raiche, 2010). The three factors together accounted for $46 \%$ of variance (Table 3 ).

The first factor accounted for $16 \%$ of variance and captured rapid automatized naming with high loadings (0.806) and phoneme substitution with smaller loadings (0.452). These two tasks are set along the sublexical route; we therefore termed the first factor $S U B$. The second factor accounted for $16 \%$ of variance and captured picture naming (0.551), semantic categorization (0.529) and rapid automatized naming (0.457) with similar loadings. Since especially the first two tasks can be associated 
Table 4 Means (standard errors in parentheses) for response times and error rates in the LDT for highfrequency four-letter words (HF4), low-frequency four-letter words (LF4), high-frequency eight-letter words (HF8), and low-frequency eight-letter words (LF8)

\begin{tabular}{lllll}
\hline & HF4 & LF4 & HF8 & LF8 \\
\hline RTs (ms) & $1594(79)$ & $1776(89)$ & $2325(115)$ & $2508(125)$ \\
Error rates $(\%)$ & $7.38(1.40)$ & $20.49(3.29)$ & $8.82(1.63)$ & $10.25(1.85)$ \\
\hline
\end{tabular}

with lexico-semantic skills, we named this factor $L E X$. The third factor accounted for $15 \%$ of variance and captured mainly letter detection with high loadings (0.905). This task is clearly visual in nature and therefore was called VIS. Rapid automatized naming entered in both the sublexical and the lexico-semantic factor. Word superiority did not load clearly on any of the factors, but only had small loadings $(0.240)$ on the VIS factor.

Importantly, the tasks that were captured within each factor are in spatial proximity in our mapping to the DRC components (cf. Fig. 1). This reflects the organizational assignment of these skills and confirms previous assumptions. We extracted the factor scores for each participant for later use in the lexical decision task analyses.

\section{Linear mixed-effects models of the lexical decision task}

In a next step, we investigated the effects of the three DRC component factors on children's length and frequency effects in a lexical decision task at the end of grade 2. To this end, the data from the lexical decision task was analyzed by using (general) linear mixed-effects models as implemented in the lme4 package (Bates et al., 2015) in R. Only analyses of the word data are presented in the following because pseudowords do not have frequencies. Reaction times and accuracies from the word items in the LDT were used as dependent variables. Length and frequency and their interaction were included as fixed effects. The scores of the three factors identified by the factor analysis, SUB, LEX, and VIS, were added as predictors, each in interaction with length and frequency. Random intercepts for Subject and Item were included. For the response time analysis, incorrect responses were removed (15.71\%), as were response times below $200 \mathrm{~ms}$ or above $8000 \mathrm{~ms}(1.85 \%)$. The remaining response times were logarithmically transformed. Following Baayen and Milin (2010), model criticism based on a simple model including random effects for subject and item was used for further outlier trimming, excluding all data points with residuals exceeding 2.5 standard deviations for the main analyses $(2.30 \%)$. Descriptive statistics are presented in Table 4. Results for the overall effects tests using contrast coding and Type III sum of squares (using the Anova function in the car package) are reported in Table 5. Post-hoc comparisons between conditions were carried out using cell means coding and single df contrasts with the glht function of the multcomp package (Hothorn et al., 2008) and were evaluated using a normal distribution. 
Table 5 Results from mixedeffect models with length, frequency, VIS, SUB, and LEX as fixed effects, and participant and item as random intercepts (all $d f=1)$

\begin{tabular}{|c|c|c|}
\hline & \multicolumn{2}{|l|}{$\chi^{2}$} \\
\hline & RTs & Errors \\
\hline \multicolumn{3}{|l|}{ Fixed effects } \\
\hline Intercept & $37,552.67 *$ & $275.58 *$ \\
\hline Length & $120.63 *$ & 2.11 \\
\hline Frequency & $7.84 *$ & $10.40^{*}$ \\
\hline Length $\times$ Frequency & $<1$ & $5.88^{*}$ \\
\hline VIS & 2.04 & $<1$ \\
\hline VIS $\times$ Length & 2.04 & $<1$ \\
\hline VIS $\times$ Frequency & $<1$ & 1.10 \\
\hline VIS $\times$ Length $\times$ Frequency & 2.49 & $<1$ \\
\hline SUB & $16.54 *$ & $11.39 *$ \\
\hline SUB $\times$ Length & $<1$ & 2.33 \\
\hline SUB $\times$ Frequency & $13.54 *$ & 2.52 \\
\hline SUB $\times$ Length $\times$ Frequency & $6.32 *$ & $<1$ \\
\hline LEX & 2.73 & $<1$ \\
\hline LEX $\times$ Length & $5.18^{*}$ & $<1$ \\
\hline LEX $\times$ Frequency & $<1$ & $<1$ \\
\hline LEX $\times$ Length $\times$ Frequency & $12.40^{*}$ & 2.26 \\
\hline \multicolumn{3}{|l|}{ Random effects } \\
\hline Participants & $3496 *$ & $331 *$ \\
\hline Items & $543 *$ & $219 *$ \\
\hline
\end{tabular}

Tests are based on Type III sum of squares and $\chi^{2}$ values with Kenward-Roger $d f$

$* p<.05$

Response time (RT) analysis of the word data revealed a significant main effect of Length, as well as Frequency, in the expected direction: RTs were shorter for four-letter words than eight-letter words and shorter for HF than LF words. There was no significant interaction between Length and Frequency. Regarding the DRC component factors, significant main effects were found for SUB only: RTs were shorter for children with higher scores in the SUB factor, $b=-0.179, z=-4.07, p<0.001$. Furthermore, there was an interaction of SUB and Frequency: children with higher SUB $(+1 \mathrm{SD})^{1}$ showed a strong frequency effect, $\Delta \mathrm{RT}=230 \mathrm{~ms}, b=0.132, z=3.83, p<0.001$, whereas children with lower SUB ( $-1 \mathrm{SD})$ did not, $\Delta \mathrm{RT}=109 \mathrm{~ms}, b=0.052, z=1.50, p=0.13$. A three-way interaction of SUB, Frequency and Length revealed that this was mainly driven by longer words: children with higher and lower SUB did not significantly differ in their frequency effect for four-letter words, which was observed for all

\footnotetext{
1 Note that the predictors SUB, LEX and VIS were included in the model as continuous variables, but for easier interpretation and direct comparison of scores above and below average, we report results for values $1 \mathrm{SD}$ above and below the mean, mirroring good and poor skills.
} 

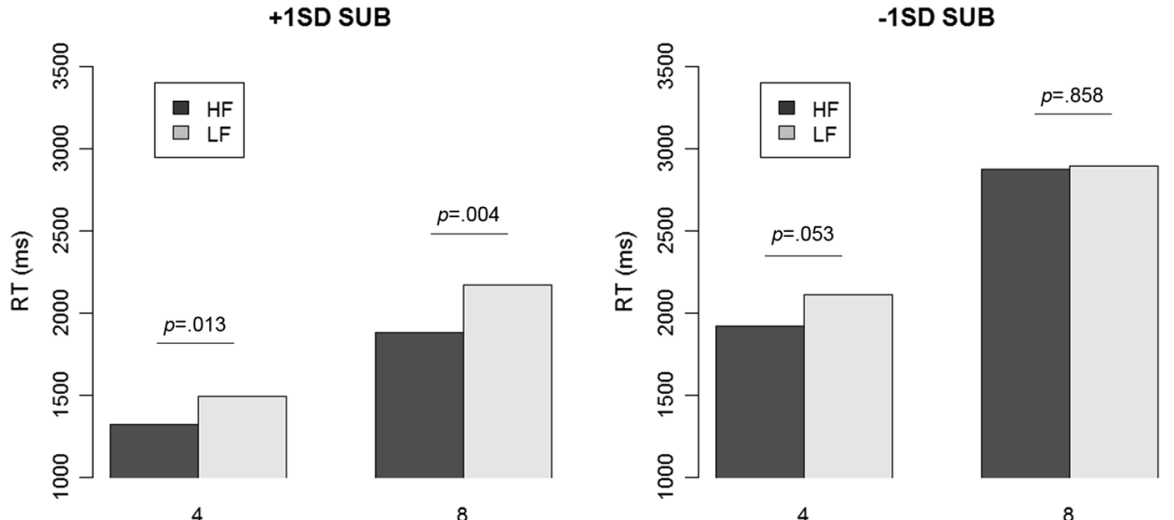

Fig. 2 Response Times in all Conditions for Readers with Higher (+1SD; left panel) and Lower (-1SD; right panel) Skills in SUB

readers, $b=0.013, z=0.81, p=0.42$. By contrast, SUB had a unique influence on the frequency effect for eight-letter words: children with higher SUB showed a frequency effect for eight-letter words, $\Delta \mathrm{RT}=289 \mathrm{~ms}, b=0.143, t=2.86$, $p=0.004$, while children with lower SUB did not, $\Delta \mathrm{RT}=25 \mathrm{~ms}, b=0.009$, $z=0.18, p=0.858$. The response times in each condition for children with higher and lower SUB skills are presented in Fig. 2.

Moreover, there was an interaction of LEX and Length: the length effect for children with higher LEX ( $+1 \mathrm{SD}), \Delta \mathrm{RT}=614 \mathrm{~ms}, b=0.332, z=9.44, p<0.001$, was smaller than for children with lower LEX ( $-1 \mathrm{SD}), \Delta \mathrm{RT}=865 \mathrm{~ms}, b=0.390$, $z=11.04, p<0.001$. A three-way interaction of LEX, Length and Frequency revealed that this was mainly the case because children with higher and lower LEX showed different frequency effects for short and long words. Children with higher LEX showed a frequency effect for four-letter words, $\Delta \mathrm{RT}=244 \mathrm{~ms}$, $b=0.155, z=3.10, p=0.002$, but they did not show a frequency effect for eightletter words, $\Delta \mathrm{RT}=72 \mathrm{~ms}, t=0.73, p=0.47$. For children with lower LEX the frequency effect was not significant for four-letter words, $\Delta \mathrm{RT}=111 \mathrm{~ms}$, $b=0.062, z=1.23, p=0.219$, but it was significant for eight-letter words, $\Delta \mathrm{RT}=316 \mathrm{~ms}, b=0.119, z=2.38, p=0.017$. The response times in each condition for children with higher and lower LEX skills are presented in Fig. 3.

The error rate analysis of the word data revealed a significant main effect of Frequency, indicating higher error rates for LF than HF words. There was also an interaction of Length and Frequency. This interaction emerged because there was a frequency effect for four-letter words, $\Delta \mathrm{ER}=13.11 \%, b=0.587, z=4.00$, $p<0.001$, but not for eight-letter words, $\Delta \mathrm{ER}=1.38 \%, b=0.083, z=0.56$, $p=0.570$. Regarding the DRC component factors, significant main effects were found for SUB only: children with higher SUB made fewer errors, indicating that they read more precisely, $b=0.336, z=3.38, p<0.001$. No other effects or interactions were significant. 
+1SD LEX

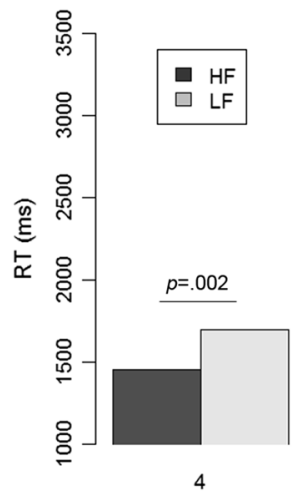

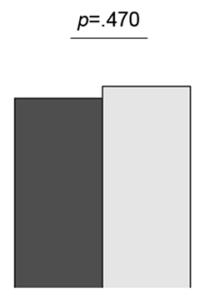

8

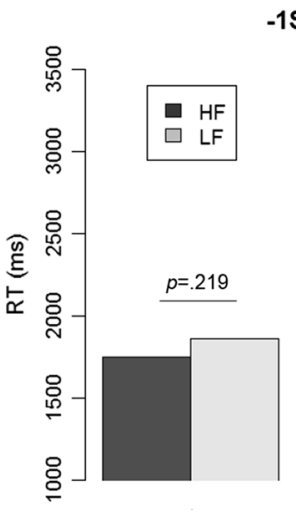

-1SD LEX

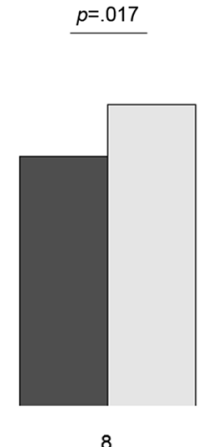

8

Fig. 3 Response Times in all Conditions for Readers with Higher (+1SD; left panel) and Lower ( 1 SD; right panel) Skills in LEX

\section{Discussion}

The present study investigated whether different precursor skills that are associated with the sublexical and lexical route of the DRC can predict individual differences in length and frequency effects as markers of sublexical and lexical reading at the end of second grade. To this end, we matched each DRC component process with a certain task (cf. Fig. 1) and measured first-graders performance on these tasks. We then conducted a factor analysis in order to verify that the skills (measured by the single tasks) cluster together in the way that the DRC suggests (cf. Fig. 1). We obtained three independent factors that showed a high theoretical correspondence to the prelexical-visual, sublexical-phonological, and the lexical-semantic components of the DRC. At the end of second grade, the same group of children performed a lexical decision task in which length and frequency were manipulated. We examined how the three DRC-related factors could predict length and frequency effects as markers for sublexical and lexical reading longitudinally. The results from our analyses indicate that individual differences in sublexical skills and lexico-semantic skills differentially predict the processing of longer words. In the following, we first discuss the results of the factor analysis and then go into detail about the influence of the factors onto length and frequency effects.

\section{Factor analysis: precursor skills as DRC component skills}

The role of phonological skills has been at the center of investigation of reading development, arguing that they are important both for initial sublexical decoding and for successful orthographic learning (e.g., Share, 1995). Additionally, efficient reading requires the use of visual, phonological, orthographic, and semantic components. Albeit their obvious importance, skills related to those other components have gained less attention. Furthermore, certain skills should be important to different extents for sublexical and lexical reading in the framework of the DRC. Our 
factor analysis extracted three distinct factors that each explained a similar amount of variance and could be aligned with the different component processes of the DRC. In particular, a first factor with loading from the letter search task constituted a visual factor (VIS), a second factor with high loading from phoneme manipulation and rapid automatized naming represented sublexical processing (SUB), and a third factor with high loading from picture naming, semantic categorization, and rapid automatized naming which involve lexico-semantic processing (LEX). This mirrors the organizational assignment of these skills (cf. Fig. 1) and empirically confirms previous theoretical assumptions.

It is notable that RAN loaded on both the sublexical and the lexico-semantic factor. This reflects its divisive role that has been a topic in previous research: some researchers have argued that it measures mostly phonological processing (e.g., Bowey, 2005; Snowling \& Hulme, 1994; Vellutino et al., 2004), whereas others have argued that it measures lexico-orthographic processing (e.g., Bowers, 1995; Bowers et al., 1994). The factor analysis suggests that it contributes to both.

It is also notable that the word superiority effect could not be assigned to any of the three factors. One needs to keep in mind, however, that the children conducted the task at the beginning of first grade when most of them were not able to read yet, thus had no stable representations in their orthographic lexicon that could lead to robust feedback effects that are at the heart of the word superiority effect (Ziegler \& Jacobs, 1995). Consequently, reliability was low and variability high in this measure (cf. Table 1). Moreover, it was the only difference measure, whereas the others were absolute response times or scores. The measure thus departed from the others in several aspects that might explain why it was not clearly assigned to any factor.

Overall, the three factors identified by means of the factor analysis provide a solid data-driven foundation for the investigation of the predictive power of certain shared or distinct sets of skills for the development of sublexical and lexical processes of reading.

\section{Lexical decision: marker effects of length and frequency}

From a developmental point of view, the DRC and other models of reading assume that children initially decode words sublexically, using grapheme-phoneme conversion, enabling them to set up orthographic representations that allow direct lexical recognition of words (e.g., Share, 1995). For the distinction of the use of sublexical and lexical reading, marker effects can be used. For the sublexical route, this is the length effect: due to the serial nature, length effects are stronger when words are decoded sublexically. For the lexical route, this is the frequency effect: abundantly encountered words are recognized faster. An increase in the reliance on lexical reading should be accompanied by decreased length effects and increased frequency effects. In line with previous studies using lexical decision (e.g., Martens \& de Jong, 2006; van den Boer et al., 2012; Burani et al., 2002), our results indicate that length effects in second-graders' RTs are still strong, indicating heavy reliance on sublexical decoding. The simultaneously observed frequency effects suggest some involvement of the lexical route. It needs to be noted that there might always be a minor role 
for frequency in LDT at the decision stage because decisions about lexical status might be easier for more frequent words, even when sublexical decoding is used, in which case phonological instead of orthographic frequencies should be of relevance.

We did not find an interaction of length and frequency in the RTs, but only in error rates. Thus, in line with other studies (e.g., Burani et al., 2002; Rau et al., 2014), length and frequency do not generally interact in developing readers. We cannot rule out that an interaction would emerge with even longer words. However, we believe that this is rather unlikely as studies reporting such an interaction used similar length ranges (e.g., Tiffin-Richards \& Schroeder, 2015).

Importantly, we found strong main effects of the DRC component factors SUB and LEX, but not VIS, on children's overall RTs in the lexical decision task. Moreover, SUB and LEX entered into differential interactions with children's length and frequency effects. This highlights that-in line with the DRC-visual abilities are rather basic skills, while the other two sets of skills have distinct influences on each of the two routes respectively. In particular, our data suggest that the interplay between sublexical and lexical reading is determined by interindividual differences in children's precursor skills that are distinctly associated with the respective components of the DRC, namely SUB and LEX. This illustrates that the division of labor still develops in beginning readers and is affected by the abilities that children bring into the reading acquisition process, in particular the relative strength of their phonological and semantic processing skills.

In particular, there was a significant interaction of length, frequency, and SUB. This interaction emerged because differences between children with lower and higher SUB skills were especially pronounced for longer HF words: children with higher SUB skills can quickly establish orthographic representations even for longer words, but only if those are encountered with sufficient frequency. This allows them to recognize those words via the lexical route. Children with lower SUB skills, by contrast, are not able to build stable orthographic representations for longer words and, consequently, do not show any frequency effects for those. This fits with the self-teaching hypothesis suggested by Share (1995) which claims that repeated successful decoding results in the establishment of orthographic representations. Similar mechanisms are also incorporated in developmental dual route models (Pritchard et al., 2018; Grainger et al., 2012) and thus supported by our findings.

Moreover, the results showed a three-way interaction of length, frequency, and LEX. This interaction can be attributed to pronounced differences between children with lower and higher LEX especially in the processing of longer low-frequency words. While even children with lower LEX manage to process infrequent short words lexically, they experience problems when infrequent words are longer. Keeping in mind that LEX captures abilities that are related to the fast retrieval of lexicosemantic information, the observed pattern suggests that children with higher LEX skills can narrow down potential word candidates already while decoding - no matter how serial or parallel decoding proceeds -, whereas children with lower LEX skills cannot retrieve possible word candidates from their lexicon before they have decoded the entire string.

These findings could be used as a basis to test how variability in SUB and LEX could be implemented in computation models. For example, in the computational 
ST-DRC model (Pritchard et al., 2018) some options would be to change the number of GPC rules provided (cf. Simulation 2 of Pritchard et al., 2018) as well as altering activation thresholds at the GPC and phoneme level or the phonological lexicon and observe the effects of this on orthographic lexicon growth and accuracy and speed of word reading.

\section{Limitations}

There are some limitations to our study. Vocabulary size is known to have a major impact on reading outcomes but entered our study only indirectly through the semantic categorization tasks and the picture naming task, which are reliant on vocabulary knowledge (Ouellette, 2006). However, as we mention above, they indicate efficiency of lexico-semantic retrieval, rather than vocabulary size itself. To disentangle the effects of lexico-semantic retrieval and vocabulary size in more detail, a separate measure of the latter would be advisable for future studies.

Another limitation concerns the word superiority effect used as a measure for functioning of the orthographic lexicon. As discussed above, it diverged from the other component measures by being a difference measure. Moreover, it exhibited high variability and low reliability. Likely, most children did not yet have an orthographic lexicon stable enough to function and be measured. Future studies should find a better way to deal with the problem of testing the absence of an orthographic lexicon.

It needs to be kept in mind that we used a lexical decision rather than a naming paradigm in second grade, albeit the DRC is primarily a model of naming. However, it can be adjusted to lexical decision by assuming access to the phonological lexicon for decision making after decoding. Moreover, there is evidence that beginning readers approach lexical decision as a naming task (Hasenäcker et al., 2019; Martens \& de Jong, 2006) in transparent orthographies.

This leads us to another possible limitation, which is that our study was restricted to German, a rather transparent orthography with few irregular words. Much work on reading development, including the developmental DRC simulation by Pritchard et al. (2018), concentrates on English. English orthography is not only opaque but has even been considered an "outlier" in terms of its irregularity and complexity in grapheme-phoneme correspondences (Share, 2008). For the future, studying a range of different languages in this regard would be desirable.

A final limitation concerns the sample of children in our study. As mentioned above, they had a medium to high socio-economic background. It would be interesting to see whether the results could be replicated with children from a lower socioeconomic background, which has been associated with lower reading achievements (Bradbury et al., 2015). Moreover, in our sample, the number of bilingual children was rather low, such that it was not possible to take L2 into account. It would be interesting to see whether the results would hold for bilingual children, that have been shown to differ in reading performance due to differences in vocabulary (Bialystock et al., 2010). 


\section{Conclusion}

Taken together, our investigation empirically confirms the mapping of different precursor skill tasks to specific components of the DRC as suggested by Ziegler et al. (2008). We were able to identify three factors that roughly correspond to the sublexical route, the lexical route, and shared visual processes (cf. Table 3). Thus, our data support the distinctiveness of the components of the DRC model and contribute to their characterization.

Secondly, results from the lexical decision experiment support the idea of a division of labor between the sublexical and lexical route in beginning readers, which seems to depend on interindividual differences in reading skills and experience.

Third, our study suggests that the ease and speed with which beginning readers can establish orthographic representations, arguably thorough self-teaching via the sublexical route, is predicted by precursor skills associated with the sublexical route. Efficiency of the orthographic route in word recognition is predicted by precursor skills associated with this route. This speaks directly to the purpose of our study, which was testing the relations between specific precursor skills and interindividual differences in the efficiency of the sublexical and lexical route in beginning readers. This, in turn, affects the relative importance of sublexical and lexical processing and determines the specific developmental path of beginning readers in the organizational space of the reading system and the developmental DRC (Pritchard et al., 2018; Rueckl, 2016).

From a methodological perspective, our study is an example of the usefulness of validating a theoretically motivated approach with a data-driven procedure. Furthermore, it is an example of expanding the research on precursor skills beyond their role for global reading ability and towards their specific role in processing mechanisms by longitudinally combining precursor assessment with experimental data. Subsequent studies should aim at disentangling how the influence of the different component skills might change over time throughout reading development. Ultimately, this line of research can have practical impact by identifying skills that need to be promoted to aid specific processes of reading development.

Funding Open Access funding enabled and organized by Projekt DEAL. This research was supported by the Max Planck Society.

Availability of data and materials Data and materials are available from the authors upon request.

Code availability Code for the analyses conducted using $\mathrm{R}$ are available from the authors upon request.

\section{Declarations}

Conflict of interest The authors state that they have no conflict of interest to declare.

Ethical standards The study was approved by the ethics committee of the Max Planck Institute for Human Development Berlin in accordance with the Declaration of Helsinki. 
Consent to participate Written informed consent to participate was obtained by the parent(s)/legal guardian(s) of the children prior to participation. In addition, oral consent was obtained from the children prior to each experimental session.

Open Access This article is licensed under a Creative Commons Attribution 4.0 International License, which permits use, sharing, adaptation, distribution and reproduction in any medium or format, as long as you give appropriate credit to the original author(s) and the source, provide a link to the Creative Commons licence, and indicate if changes were made. The images or other third party material in this article are included in the article's Creative Commons licence, unless indicated otherwise in a credit line to the material. If material is not included in the article's Creative Commons licence and your intended use is not permitted by statutory regulation or exceeds the permitted use, you will need to obtain permission directly from the copyright holder. To view a copy of this licence, visit http://creativecommons.org/licen ses/by/4.0/.

\section{References}

Araújo, S., Reis, A., Petersson, K. M., \& Faísca, L. (2015). Rapid automatized naming and reading performance: A meta-analysis. Journal of Educational Psychology, 107, 868-883. https://doi.org/10. 1037/edu0000006

Baayen, R. H., \& Milin, P. (2010). Analyzing reaction times. International Journal of Psychological Research, 3(2), 12-28.

Bates, D., Mächler, M., Bolker, B., \& Walker, S. (2015). Fitting linear mixed-effects models using lme4. Journal of Statistical Software. https://doi.org/10.18637/jss.v067.i01

Ben-Dror, I., Bentin, S., \& Frost, R. (1995). Semantic, phonologic, and morphologic skills in reading disabled and normal children: Evidence from perception and production of spoken Hebrew. Reading Research Quarterly, 30, 876. https://doi.org/10.2307/748202

Bialystok, E., Luk, G., Peets, K.F. \& Yang, S. (2010). Receptive vocabulary differences in monolingual and bilingual children. Bilingualism: Language and Cognition, 13(4), 525-531. https://doi.org/10. 1017/S1366728909990423.

Bowers, P. (1995). Tracing symbol naming speed's unique contributions to reading disabilities over time. Reading and Writing: An Interdisciplinary Journal, 7, 189-216. https://doi.org/10.1007/bf01027185

Bowers, P., Golden, J., Kennedy, A., \& Young, A. (1994). Limits upon orthographic knowledge due to processes indexed by naming speed. Neuropsychology and Cognition, 8, 173-218. https://doi.org/ 10.1007/978-94-017-3492-9_6

Bowey, J. A. (2005). Predicting individual differences in learning to read. In M. J. Snowling, \& C. Hulme (Eds.), The science of reading: A handbook (pp. 155-172). Oxford: Blackwell. https://doi.org/10. 1002/9780470757642.ch9.

Bradbury, B., Corak, M., Waldfogel, J., \& Washbrook, E. (2015). Too many children left behind: The U.S. achievement gap in comparative perspective. Russell Sage Foundation.

Brysbaert, M., Mandera, P., \& Keuleers, E. (2018). The word frequency effect in word processing: An updated review. Current Directions in Psychological Science, 27, 45-50. https://doi.org/10.1177/ 0963721417727521

Burani, C., Marcolini, S., \& Stella, G. (2002). How early does morpholexical reading develop in readers of a shallow orthography? Brain and Language, 81, 568-586. https://doi.org/10.1006/brln.2001. 2548

Caravolas, M., Lervåg, A., Mousikou, P., Efrim, C., Litavský, M., Onochie-Quintanilla, E., Salas, N., Schöffelová, M., Defior, S., Mikulajová, M., Seidlová-Málková, G., \& Hulme, C. (2012). Common patterns of prediction of literacy development in different alphabetic orthographies. Psychological Science, 23, 678-686. https://doi.org/10.1177/0956797611434536

Castles, A., Rastle, K., \& Nation, K. (2018). Ending the reading wars: Reading acquisition from novice to expert. Psychological Science in the Public Interest, 19(1), 5-51. https://doi.org/10.1177/15291 00618772271. 
Chang, Y.-N., \& Monaghan, P. (2018). Quantity and diversity of preliteracy language exposure both affect literacy development: Evidence from a computational model of reading. Scientific Studies of Reading, 23, 235-253. https://doi.org/10.1080/10888438.2018.1529177

Chang, Y.-N., Monaghan, P., \& Welbourne, S. (2019). A computational model of reading across development: Effects of literacy onset on language processing. Journal of Memory and Language, 108, 104025. https://doi.org/10.1016/j.jml.2019.05.003

Coltheart, M., Rastle, K., Perry, C., Langdon, R., \& Ziegler, J. (2001). DRC: A dual route cascaded model of visual word recognition and reading aloud. Psychological Review, 108, 204-256. https:// doi.org/10.1037/0033-295x.108.1.204

De Jong, P. F., \& van der Leij, A. (2003). Developmental changes in the manifestation of a phonological deficit in dyslexic children learning to read a regular orthography. Journal of Educational Psychology, 95, 22-40. https://doi.org/10.1037/0022-0663.95.1.22

de Jong, P. F., \& van der Leji, A. (1999). Specific contributions of phonological abilities to early reading acquisition: Results from a Dutch latent variable longitudinal study. Journal of Educational Psychology, 91, 450-476. https://doi.org/10.1037/0022-0663.91.3.450

Ennemoser, M., Marx, P., Weber, J., \& Schneider, W. (2012). Spezifische Vorläuferfertigkeiten der Lesegeschwindigkeit, des Leseverständnisses und des Rechtschreibens. (Specific precursor skills of reading speed, reading comprehension and writing). Zeitschrift Für Entwicklungspsychologie Und Pädagogische Psychologie, 44, 53-67. https://doi.org/10.1026/0049-8637/a000057

Glaser, W. R. (1992). Picture naming. Cognition, 42, 61-105. https://doi.org/10.1016/0010-0277(92) 90040-o

Grainger, J., Lété, B., Bertand, D., Dufau, S., \& Ziegler, J. C. (2012). Evidence for multiple routes in learning to read. Cognition, 123(2), 280-292. https://doi.org/10.1016/j.cognition.2012.01.003.

Harm, M. W., \& Seidenberg, M. S. (2004). Computing the meanings of words in reading: Cooperative division of labor between visual and phonological processes. Psychological Review, 111(3), 662720. https://doi.org/10.1037/0033-295x.111.3.662.

Hasenäcker, J., Verra, L., \& Schroeder, S. (2019). Comparing length and frequency effects in children across modalities. Quarterly Journal of Experimental Psychology, 72, 1682-1691. https://doi. org/10.1177/1747021818805063

Hothorn, T., Bretz, F., \& Westfall, P. (2008). Simultaneous inference in general parametric models. Biometrical Journal, 50(3), 346-363. https://doi.org/10.1002/bimj.200810425.

Huestegge, L., Radach, R., Corbic, D., \& Huestegge, S. M. (2009). Oculomotor and linguistic determinants of reading development: A longitudinal study. Vision Research, 49, 2948-2959. https:// doi.org/10.1016/j.visres.2009.09.012

Hyönä, J., \& Olson, R. K. (1995). Eye fixation patterns among dyslexic and normal readers: Effects of word length and word frequency. Journal of Experimental Psychology: Learning, Memory, and Cognition, 21, 1430-1440. https://doi.org/10.1037/0278-7393.21.6.1430

Jackson, N. E., \& Coltheart, M. (2001). Routes to reading success and failure: Toward an integrated cognitive psychology of atypical reading. Taylor \& Francis.

Keuleers, E., \& Brysbaert, M. (2010). Wuggy: A multilingual pseudoword generator. Behavior Research Methods, 42, 627-633. https://doi.org/10.3758/brm.42.3.627

Landerl, K., Freudenthaler, H. H., Heene, M., de Jong, P. F., Desroches, A., Manolitsis, G., \& Parrila, R. (2018). Phonological awareness and rapid automatized naming as longitudinal predictors of reading in five alphabetic orthographies with varying degrees of consistency. Scientific Studies of Reading, 23, 220-234. https://doi.org/10.1080/10888438.2018.1510936

Landerl, K., \& Wimmer, H. (2008). Development of word reading fluency and spelling in a consistent orthography: An 8-year follow-up. Journal of Educational Psychology, 100, 150-161. https:// doi.org/10.1037/0022-0663.100.1.150

Landerl, K., Wimmer, H., \& Frith, U. (1997). The impact of orthographic consistency on dyslexia: A German-English comparison. Cognition, 63, 315-334. https://doi.org/10.1016/s0010-0277(97) 00005-x

Martens, V. E. G., \& de Jong, P. F. (2006). The effect of word length on lexical decision in dyslexic and normal reading children. Brain and Language, 98, 140-149. https://doi.org/10.1016/j.bandl. 2006.04.003

Melby-Lervåg, M., Lyster, S.-A.H., \& Hulme, C. (2012). Phonological skills and their role in learning to read: A meta-analytic review. Psychological Bulletin, 138, 322-352. https://doi.org/10.1037/ $\mathrm{a} 0026744 f$ 
Moll, K., Fussenegger, B., Willburger, E., \& Landerl, K. (2009). RAN is not a measure of orthographic processing. Evidence from the asymmetric German orthography. Scientific Studies of Reading, 13, 1-25. https://doi.org/10.1080/10888430802631684

Moll, K., \& Landerl, K. (2010). SLRT-II: Lese- und Rechtschreibtest: Weiterentwicklung der Salzburger Lese- und Rechtschreibtests (SLRT): Manual [SLRT-II: Reading and writing test: Advancement of the Salzburg reading and writing test (SLRT)]. Verlag Hans Huber.

Moll, K., Ramus, F., Bartling, J., Bruder, J., Kunze, S., Neuhoff, N., \& Landerl, K. (2014). Cognitive mechanisms underlying reading and spelling development in five European orthographies. Learning and Instruction, 29, 65-77. https://doi.org/10.1016/j.learninstruc.2013.09.003

Ouellette, G. (2006). What's meaning got to do with it: The role of vocabulary in word reading and reading comprehension. Journal of Educational Psychology, 98(3), 554-566. https://doi.org/10. 1037/0022-0663.98.3.554

Pauly, H., Linkersdörfer, J., Lindberg, S., Woerner, W., Hasselhorn, M., \& Lonnemann, J. (2011). Domain-specific rapid automatized naming deficits in children at risk for learning disabilities. Journal of Neurolinguistics, 24, 602-610. https://doi.org/10.1016/j.jneuroling.2011.02.002

Perry, C., Zorzi, M., \& Ziegler, J. C. (2019). Understanding dyslexia through personalized large-scale computational models. Psychological Science, 30, 386-395. https://doi.org/10.1177/0956797618 823540

Pritchard, S. C., Coltheart, M., Marinus, E., \& Castles, A. (2018). A computational model of the selfteaching hypothesis based on the Dual-Route Cascaded model of reading. Cognitive Science, 42, 722-770. https://doi.org/10.1111/cogs.12571

R Development Core Team (2008). R: A language and environment for statistical computing. R Foundation for Statistical Computing, Vienna, Austria. ISBN 3-900051-07-0. http://www.R-project.org.

Raiche, G. (2010). An R package for parallel analysis and non graphical solutions to the Cattell scree test. $\mathrm{R}$ package version 2.3.3.1. https://CRAN.R-project.org/package=nFactors.

Rau, A. K., Moeller, K., \& Landerl, K. (2014). The transition from sublexical to lexical processing in a consistent orthography: An eye-tracking study. Scientific Studies of Reading, 18, 224-233. https:// doi.org/10.1080/10888438.2013.857673

Rau, A. K., Moll, K., Moeller, K., Huber, S., Snowling, M. J., \& Landerl, K. (2016). Same same, but different: Word and sentence reading in German and English. Scientific Studies of Reading, 20(3), 203-219. https://doi.org/10.1080/10888438.2015.1136913

Reicher, G. M. (1969). Perceptual recognition as a function of meaningfulness of stimulus material. Journal of Experimental Psychology, 81, 275-280. https://doi.org/10.1037/h0027768

Rueckl, J. G. (2016). Toward a theory of variation in the organization of the word reading system. Scientific Studies of Reading, 20, 86-97. https://doi.org/10.1080/10888438.2015.1103741

Schmalz, X., Marinus, E., Coltheart, M., \& Castles, A. (2015). Getting to the bottom of orthographic depth. Psychonomic Bulletin \&amp; Review, 22, 1614-1629. https://doi.org/10.3758/ s13423-015-0835

Schroeder, S., Würzner, K.-M., Heister, J., Geyken, A., \& Kliegl, R. (2014). childLex: A lexical database of German read by children. Behavior Research Methods, 47, 1085-1094. https://doi.org/10.3758/ s13428-014-0528-1

Schröter, P., \& Schroeder, S. (2017). The Developmental Lexicon Project: A behavioral database to investigate visual word recognition across the lifespan. Behavior Research Methods. https://doi.org/10. 3758/s13428-016-0851-9

Share, D. L. (1995). Phonological recoding and self-teaching: Sine qua non of reading acquisition. Cognition, 55, 151-218. https://doi.org/10.1016/0010-0277(94)00645-2

Share, D. L. (1999). Phonological recoding and orthographic learning: A direct test of the self-teaching hypothesis. Journal of Experimental Child Psychology, 72, 95-129. https://doi.org/10.1006/jecp. 1998.2481

Share, D. L. (2008). On the Anglocentricities of current reading research and practice: The perils of overreliance on an "outlier" orthography. Psychological Bulletin, 134, 584-615. https://doi.org/10.1037/ 0033-2909.134.4.584

Snowling, M. J., \& Hulme, C. (Eds.). (1994). Reading development and dyslexia. London, UK: Whurr.

Spinelli, D., De Luca, M., Di Filippo, G., Mancini, M., Martelli, M., \& Zoccolotti, P. (2005). Length effect in word naming in reading: Role of reading experience and reading deficit in Italian readers. Developmental Neuropsychology, 27, 217-235. https://doi.org/10.1207/s15326942dn2702_2

Stock, C., Marx, P., \& Schneider, W. (2003): BAKO 1-4. Basiskompetenzen für Lese-Rechtschreibleistungen. Ein Test zur Erfassung der phonologischen Bewusstheit vom ersten bis vierten Grundschuljahr. 
(BAKO 1-4. Basic competencies for reading and writing abilites. A test of phonological awareness from grade one through four.) Göttingen: Beltz Test GmbH.

Swan, D., \& Goswami, U. (1997). Picture naming deficits in developmental dyslexia: The phonological representations hypothesis. Brain and Language, 56, 334-353. https://doi.org/10.1006/brln.1997. 1855

Szekely, A., Jacobsen, T., D’Amico, S., Devescovi, A., Andonova, E., Herron, D., Lug, C. C., Pechmann, T., Pléh, C., Wicha, N., Federmeier, K., Gerdjikova, I., Gutierrez, G., Hung, D., Hsug, J., Iyer, G., Kohnert, K., Mehotcheva, T., Orozco-Figueroa, A., et al. (2004). A new on-line resource for psycholinguistic studies. Journal of Memory and Language, 51, 247-250. https://doi.org/10.1016/j.jml. 2004.03.002

Tiffin-Richards, S. P., \& Schroeder, S. (2015). Word length and frequency effects on children's eye movements during silent reading. Vision Research, 113, 33-43. https://doi.org/10.1016/j.visres.2015.05. 008

Torgesen, J. K., Wagner, R. K., Rashotte, C. A., Burgess, S., \& Hecht, S. (1997). Contributions of phonological awareness and rapid automatic naming ability to the growth of word-reading skills in second- to fifth-grade children. Scientific Studies of Reading, 1, 161-185. https://doi.org/10.1207/s1532 799xssr0102_4

Van den Boer, M., \& de Jong, P. F. (2015). Parallel and serial reading processes in children's word and nonword reading. Journal of Educational Psychology, 107(1), 141-151. https://doi.org/10.1037/ a0037101.

Van den Boer, M., de Jong, P. F., \& Haentjens-van Meeteren, M. M. (2012). Lexical decision in children: Sublexical processing or lexical search? The Quarterly Journal of Experimental Psychology, 65, 1214-1228. https://doi.org/10.1080/17470218.2011.652136

Van den Boer, M., de Jong, P. F., \& Haentjens-van Meeteren, M. M. (2013). Modeling the length effect: Specifying the relation with visual and phonological correlates of reading. Scientific Studies of Reading, 17(4), 243-256. https://doi.org/10.1080/10888438.2012.683222.

Vellutino, F. R., Fletcher, J. M., Snowling, M. J., \& Scanlon, D. M. (2004). Specific reading disability (dyslexia): What have we learned in the past four decades? Journal of Child Psychology and Psychiatry, 45, 2-40. https://doi.org/10.1046/j.0021-9630.2003.00305.x

Wagner, R. K., \& Torgesen, J. K. (1987). The nature of phonological processing and its causal role in the acquisition of reading skills. Psychological Bulletin, 101, 192-212. https://doi.org/10.1037/00332909.101.2.192

Ziegler, J. C., Bertrand, D., Tóth, D., Csépe, V., Reis, A., Faísca, L., Saine, N., Lyytinen, H., Vaessen, A., \& Blomert, L. (2010). Orthographic depth and its impact on universal predictors of reading. Psychological Science, 21(4), 551-559. https://doi.org/10.1177/0956797610363406

Ziegler, J. C., Castel, C., Pech-Georgel, C., George, F., Alario, F.-X., \& Perry, C. (2008). Developmental dyslexia and the dual route model of reading: Simulating individual differences and subtypes. $\mathrm{Cog}$ nition, 107, 151-178. https://doi.org/10.1016/j.cognition.2007.09.004

Ziegler, J., \& Jacobs, A. M. (1995). Phonological information provides early sources of constraint in the processing of letter strings. Journal of Memory and Language, 34, 567-593. https://doi.org/10. 1006/jmla.1995.1026

Ziegler, J. C., Perry, C., \& Coltheart, M. (2000). The DRC model of visual word recognition and reading aloud: An extension to German. European Journal of Cognitive Psychology, 12, 413-430. https:// doi.org/10.1080/09541440050114570

Ziegler, J. C., Perry, C., Ma-Wyatt, A., Ladner, D., \& Schulte-Körne, G. (2003). Developmental dyslexia in different languages: Language-specific or universal? Journal of Experimental Child Psychology, 86, 169-193. https://doi.org/10.1016/s0022-0965(03)00139-5

Ziegler, J. C., Perry, C., \& Zorzi, M. (2014). Modelling reading development through phonological decoding and self-teaching: Implications for dyslexia. Philosophical Transactions of the Royal Society B: Biological Sciences, 369, 20120397. https://doi.org/10.1098/rstb.2012.0397

Zoccolotti, P., De Luca, M., Di Pace, E., Gasperini, F., Judica, A., \& Spinelli, D. (2005). Word length effect in early reading and in developmental dyslexia. Brain and Language, 93, 369-373. https://doi. org/10.1016/j.bandl.2004.10.010

Publisher's Note Springer Nature remains neutral with regard to jurisdictional claims in published maps and institutional affiliations. 